\title{
summary
}

\section{Subgingival doxycycline as effective as scaling and root planing in reducing the clinical signs of adult periodontitis}

Garrett S, Johnson L, Drisko CH, Adams DF, Bandt C, Beiswanger B, Bogle G, Donly K, Hallmon WW, Hancock EB, Hanes $P$, Hawley CE, Kiger R, Killoy W, Mellonigg JT, Polson A, Raab FJ, Ryder M, Stoller NH, Horn-Lay Wang, Wolinsky LE, Evans GH, Harrold CQ, Arnold RM, Atack DF, Fitzgerald B, Hill M, Issacs RL, Nasi HF, Newell DH, MacNeil RL, MacNeill S, Spolsky VW, Duke SP, Polson A, Southard GL. Two Multi-Centre Studies evaluating locally delivered doxycycline hyclate, placebo control, oral hygiene and scaling and root planing in the treatment of periodontitis. J Periodontol 1999; 70: 490-503

Objective To test the safety and effectiveness of doxycycline hyclate delivered subgingivally to human periodontal pockets in a biodegradable controlled-release delivery system.

Design Multi-centre, randomised single-blind study

Intervention Patients with generalised moderate to severe periodontitis (two quadrants with more than four pockets $\geqslant 5 \mathrm{~mm}$ which bled on probing at least two sites must be $\geqslant 7 \mathrm{~mm}$ ) were randomised to receive one of the following treatments; subgingival doxycycline hyclate $(\mathrm{DH})$, subgingival placebo (VC), oral hygiene $(\mathrm{OH})$ or scaling and root planing (SRP). Patients were excluded if they were receiving a contraindicated medication, or had received SRP within 2 months. DH and VC patients also had periodontal dressings, which were removed at 7 days together with test material. Blind evaluation of treatment was carried out.

Outcome measures Clinical attachment gain, probing depth reduction, plaque score and adverse events

Results Mean and frequency data for clinical attachment and probing depth changes over the 9-month period are given, as are plaque scores. Adverse events (mild to moderate gingival soreness) were also noted with 38 in DH group, 51 in VC, 10 in $\mathrm{OH}$ and 35 in SRP. Numbers

\begin{tabular}{|c|c|c|c|c|c|}
\hline \multicolumn{2}{|c|}{$\begin{array}{l}\text { Percentage of sites at } \\
9 \text { months showing }\end{array}$} & $\mathrm{DH}$ & VC & $\mathrm{OH}$ & SRP \\
\hline \multirow{2}{*}{$\begin{array}{l}\text { Attachment gain } \\
\geqslant 3 \mathrm{~mm}\end{array}$} & Study 1 & 11 & 7 & 5 & 8 \\
\hline & Study 2 & 11 & 6 & 7 & 11 \\
\hline \multirow{4}{*}{$\begin{array}{l}\text { Probing depth } \\
\text { reduction } \geqslant 3 \mathrm{~mm}\end{array}$} & Study 1 & 10 & 6 & 4 & 9 \\
\hline & Study 2 & 14 & 8 & 6 & 17 \\
\hline & & NNT & $\mathrm{NNH}$ & & \\
\hline & $\begin{array}{l}\mathrm{OH} \\
\mathrm{OH} \\
\mathrm{OH}\end{array}$ & $\begin{array}{l}17 \\
50 \\
20\end{array}$ & $\begin{array}{l}7 \\
5 \\
9\end{array}$ & & \\
\hline
\end{tabular}

needed to treat (NNT) and harm (NNH) were calculated from data presented in study.

Conclusion Subgingival doxycycline hyclate is equally effective as scaling and root planing and superior to placebo and oral hygiene in reducing the clinical signs of adult periodontitis over 9 months.

Address for reprints: Dr Steven Garrett, Atrix Laboratories, Inc, 2579 Modpoint Drive, Fort Collins, CO 80525, USA.

\section{Commentary}

The elimination or alteration of the microbial pathogens present in subgingival plaque is the primary object of periodontal therapy, to stop the progression of the infection that causes the progressive destruction of the supporting periodontal apparatus. The traditional nonsurgical approach is to perform scaling and root planning. Recently other less invasive approaches have been suggested. One of them is to use doxycycline hyclate delivered with a biodegradable delivery system that provides a controlled release of the medication.

The studies in this report were designed to test the safety and effectiveness of doxycycline hyclate. This carefully planned study forms the basis for the clinical portion of the New Drug Application with the US Food and Drug Administration for acceptance of this product to treat human periodontitis. Four hundred and eleven patients were treated on each one of the studies; 375 patients completed study 1, and 383 completed study 2 .

The four procedures compared - locally delivered doxycycline hyclate, placebo control, oral hygiene and scaling and root planning - were randomly assigned to each patient of this single-blind study. A doubleblind design was not possible, according to the authors, because of the dissimilar treatments between various treatment groups. The most important outcomes measured were mean change in attachment level and probing depth and all statistical tests were conducted at a significance level of $P<0.05$.

What is important is whether this new treatment offers any improvement to the traditional treatment of periodontitis. As the authors discuss, one of the problems with the delivery methods for pharmacologic agents in the periodontal pocket it is the turnover of gingival fluid. Their doxycycline system is a 'controlled delievery device' providing the active agent for 7-10 days.

The results of this study could probably be applied to any population, but always following a careful design, like this one. However, one of the authors' conclusions states that doxycycline hyclate and scaling and root planning result in clinically equivalent results in both attachment level gain and probing depth, so it could be said that there is not a real improvement over the traditional and proven treatment of periodontitis. More data on these studies will be published and it is possible that doxycycline hyclate could be a useful addition to currently available treatments.

Hector J Rodriguez Periodoncia Asturiana, Spain 